\title{
GENETIC TRACEABILITY OF SELECTED POPULATIONS OF THE YELLOWSTRIPE SCAD, SELAROIDES LEPTOLEPIS (ACTINOPTERYGII: PERCIFORMES: CARANGIDAE), BASED ON THE ANALYSIS OF MICROSATELLITE DNA—CELFISH PROJECT—PART 3
}

\author{
Jolanta KEMPTER ${ }^{1 *}$, Maciej KIELPINSKI ${ }^{1}$, Remigiusz PANICZ ${ }^{1}$, Kinga MIKOLAJCZYK², \\ and Slawomir KESZKA ${ }^{1}$ \\ ${ }^{1}$ Division of Aquaculture, Faculty of Food Science and Fisheries, \\ West Pomeranian University of Technology, Szczecin, Poland \\ ${ }^{2}$ Division of Genetics and Animal Breeding, Faculty of Biotechnology and Animal Husbandry, \\ West Pomeranian University of Technology, Szczecin, Poland
}

Kempter J., Kielpiński M., Panicz R., Mikolajczyk K., Keszka S. 2015. Genetic traceability of selected populations of the yellowstripe scad, Selaroides leptolepis (Actinopterygii: Perciformes: Carangidae), based on the analysis of microsatellite DNA—CELFISH Project—Part 3. Acta Ichthyol. Piscat. 45 (3): 299-305.

Background. Monitoring the genetic diversity of fish populations can provide information necessary to determine fishing quotas for the commercially caught species. One of the species subjected to intensive exploitation is the yellowstripe scad, Selaroides leptolepis (Cuvier, 1833), commonly occurring in the coastal waters of Vietnam, Cambodia, Malaysia, and Indonesia. This paper is the third part of a larger project: "Development of a genetic-based system for identification of food products from fisheries and aquaculture introduced to the European Union customs area".

Materials and methods. Fin fragments of the yellowstripe scad, Selaroides leptolepis, were obtained in 2012 and 2013 from local markets in Vietnam (SVN), Cambodia (SKH), Malaysia (MMY), and Indonesia (MID). The analyses focused on the amplification and sequencing of a fragment of the nuclear rhodopsin gene which utilized as identification label. Subsequently, in the obtained SVN, SKH, MMY, and MID samples, 11 microsatellite regions (SRR) were analysed. Sequence analyses were performed using the BioEdit and BLAST software, while the analysis of the obtained SRR data was conducted using the GenAlEx software.

Results. The analysis of the obtained loci variants divided the investigated populations into two genetically homogeneous groups: the Vietnamese-Indonesian group and the Malaysian-Cambodian group. The analysis of genetic diversity revealed statistically significant deviations from the Hardy-Weinberg equilibrium in the investigated populations and indicated the Vietnamese population as the most stable, while the Malaysian population as the least stable.

Conclusions. The study provides information on the genetic diversity of the investigated populations and allows assignment of the captured fish to the geographical regions specified. Moreover, indicate that among analysed populations the safest populations were those caught in the local fisheries (continental shelf) of Vietnam and Cambodia due to their high mean genetic diversity.

Keywords: microsatellite, genetic variation, seafood authentication, seafood counterfeiting

\section{INTRODUCTION}

Genetic identification of food ingredients is an important method that enables the traceability and confirmation of authenticity of fish products. With regard to common cases in which valuable fish species are replaced by low-value equivalents, it is necessary to provide reliable methods which would precisely identify those fish species that are valuable for the economy. These methods help to eliminate counterfeit products from markets but also provide tools that might be used by governmental units which control food safety, including custom services. Population identification using molecular methods also provides information about catch region (Anonymous 2015a), which is highly useful in protection strategies of overfished populations, or catches of the IUU group (Illegal, Unreported, and Unregulated). 
The results presented in this paper are part of the work carried out within the scientific research project "Development of a genetic-based system for identification of food products form fisheries and aquaculture introduced to the European Union customs area" funded by the European Union within 2011-2013.

Species of the family Carangidae are the fifth most intensively exploited fish group, following gadoids (Gadidae) (Anonymous 2015b). The yellowstripe scad, Selaroides leptolepis (Cuvier, 1833), is a marine pelagic species occurring in the waters of the Indian Ocean and Pacific, from the Persian Gulf to the Philippines, northern Japan, as well as the south coast of the Arafura Sea and Australia. The maximum body size is $22 \mathrm{~cm}$ and the weight does not exceed $625 \mathrm{~g}$ (Froese and Pauly 2014). The species is the only representative of the genus Selaroides, (family Carangidae), that feeds mainly on mussels and snails, which classifies the species as predatory. In terms of human consumption, it is a species of an average taste value of the meat, consumed mainly as dried fish or used for the preparation of stuffing for burgers, but also sold locally as whole fish, either fresh or frozen. Studies have shown that due to the high content of red meat combined with the high content of fat and mioglobin, the species is used for the production of high-quality surimi in Asia (Arfat and Benjakul 2012).

Selaroides leptolepis is known in Malaysia and Indonesia under the local name of "kuning" and its market price is within the average values for fish for human consumption (Sumaila et al. 2007). In the European Union, the yellowstripe scad was imported as part of the scad fish group without a clear indication of a particular species. Within 5 years, there were 57 reports of this species mainly from New Zealand and Sri Lanka (Skrzypczak unpublished). Global catches of the species in 2011 were approximately $200000 \mathrm{t}$, while in 2012 the value decreased to $198600 \mathrm{t}$ (Anonymous 2015b). The natural resources of the yellowstripe scad are most intensively exploited in Malaysia (41 $341 \mathrm{t}$ ) and United Arab Emirates (3196 t). According to Tan and Yap (2006), the species is the third most intensively captured species after Rastrelliger kanagurta (Cuvier, 1816) and Decapterus maruadsi (Temminck et Schlegel, 1843). It is also reported as trawling bycatch in Australia (Dell et al. 2009). Among the nets used for fishing are mainly seines, trawls, trapping devices, and nets with a mesh size of up to $20 \mathrm{~mm}$ (typically $15 \mathrm{~mm}$ ). The species status according to IUCN is not evaluated, i.e., not assessed according to the IUCN criteria. The population of that species is rather poorly characterized which is probably due to underestimation of the nutritional value of the S. leptolepis meat, as well as the limited activities for the protection of stocks in countries such as Indonesia, Malaysia, and Vietnam, where the species constitutes native ichthyofauna. These countries are mainly focused on aquaculture, whereas the commonly fished wild species are not a subject of population studies. In the Philippines, the yellowstripe scad is defined as one of the most often caught species, apart from Decapterus macrosoma Bleeker, 1851; Selaroides leptolepis (Cuvier, 1833); and Rastrelliger kanagurta, although a population analysis allowed the conclusion that the species is exploited too heavily (Rueca et al. 2009). According to Tandon (1964) "overfishing of marine species and ineffective reintroduction necessitate scientific research aimed at species identification, a well as the spatial and temporal modes of spreading of ichthyofauna stocks." The economic significance of the species is high as it is inexpensive and although it is captured using nets with too large mesh (no selectivity of fishing), it still covers the bulk of the protein demand of local populations. The potential for confusion with other species (Gunn 1990) is primarily due to the morphological similarity and overlapping of the areas of occurrence of 2 species: Selar boops (Cuvier, 1833) and Selar crumenophthalmus (Bloch, 1793). The latter is particularly valued in northern Australia, reaching very high prices. Visual identification of such products is very difficult and often impossible. Past experience and controls carried out by various institutions indicate that, for a variety of reasons, the declared fish species does not always correspond to the contents of the package (Jacquet and Pauly 2008).

The lack of information necessary to assess the genetic stability of the yellowstripe scad, a relevant species from both economic and ecological point of view, convinced the authors to perform genetic analysis of selected populations of the species.

\section{MATERIAL AND METHODS}

The study material consisted of fin sections from juvenile individuals of the yellowstripe scad, Selaroides leptolepis, obtained in 2012 and 2013 from local markets in Phan Thiet, Vietnam (SVN), Phnom Penh, Cambodia (SKH), Malacca, Malaysia (MMY), and Jakarta, Indonesia (MID).

The collected fin fragments of the SVN $(n=8)$, SKH $(n=7)$, MMY $(n=11)$, and MID $(n=8)$ populations were dried for transport and then conserved in $5 \mathrm{~mL}$ tubes containing silicone medium. DNA isolation from fin sections was performed using the peqGOLD Tissue DNA Mini Kit (peqlab) following the attached protocol. The qualitative and quantitative assessment of the isolates was carried out by electrophoresis in $1.5 \%$ agarose gel followed by spectrophotometric measurements using the NanoDrop 2000 instrument (Thermo Scientific). For all investigated samples, PCR amplification of a fragment of the nuclear rhodopsin gene (RH1) was conducted using the primers Rod-F2W and Rod-R4n in accordance with the methodology proposed by Sevilla et al. (2007). Subsequently, in the obtained SVN, SKH, MMY, and MID samples, 11 microsatellite regions (SRR) were analysed: Orla 21-231, Orla 16-32, Orla 2-91, Orla 22-135, Orla 5-131, Orla 12-160, Orla 16-185, Orla 8-113, Orla 9-204, Orla 9-38, and Orla 20-134. The amplification of the regions was conducted in accordance with the methodology used by Gotoh et al. (2013). The standard PCR profile was modified to that of touchdown PCR: $94^{\circ} \mathrm{C}$ for $5 \mathrm{~min}$, then 30 cycles of denaturation $\left(94^{\circ} \mathrm{C}, 45 \mathrm{~s}\right)$, primer annealing $\left(62^{\circ} \mathrm{C}, 30 \mathrm{~s} \times 7\right.$ and $\left.59^{\circ} \mathrm{C}, 30 \mathrm{~s} \times 27\right)$, and elongation $\left(72^{\circ} \mathrm{C}, 20 \mathrm{~s}\right)$, followed by final elongation at $72^{\circ} \mathrm{C}$ for $7 \mathrm{~min}$. The reaction mix was prepared based on the GoTaq ${ }^{\circledR}$ G2 Hot Start polymerase (Promega), Green Master Mix $12.5 \mu \mathrm{L}$, F-primer $0.5 \mu \mathrm{L}\left(10 \mathrm{pmol} \cdot \mu \mathrm{L}^{-1}\right)$, R-primer 
$0.5 \mu \mathrm{L}\left(\mathrm{pmol} \cdot \mu \mathrm{L}^{-1}\right), \mathrm{H}_{2} \mathrm{O}$ DEPC $10.5 \mu \mathrm{L}$, DNA $1 \mu \mathrm{L}$. All PCR amplifications were carried out on a GeneAmp ${ }^{\circledR}$ PCR System 9700 thermocycler (Applied Biosystems) and the results were evaluated by amplicon electrophoresis in $2 \%$ agarose gel. Sequencing of the obtained RH1 PCR products was ordered from Genomed, Warsaw, Poland. Analysis of thus obtained sequences was performed using the BioEdit software and BLAST (Altschul et al. 1990, Hall 1999). The separation of SRR fragments was carried out using the SEQ 8000 sequencer (Beckman Coulter), while the analysis of the obtained SRR data was conducted using the GenAlEx software (Peakall and Smouse 2012).

\section{RESULTS}

Comparing the nucleotide sequences of the rhodopsin gene from the SVN, SKH, MMY, and MID samples in the BioEdit software revealed no differences between SVN and MID, and between MMY and SKH. Differences were observed between: SVN and SKH, SVN and MMY, MID and SKH, and MID and MMY. The RH1 sequences were compared with those submitted to GenBank using BLAST and it was found that there was no $100 \%$ overlap between the compared sequences and those from GenBank. No sequences originating from this species were also found. A preliminary analysis of the SSR markers demonstrated that all investigated loci in the four populations were polymorphic and, therefore, qualified for further analysis. The total number of alleles for the SVN, SKH, MMY, and MID populations was $89,85,114$, and 70 , respectively, while the total number of alleles of the investigated loci was 4-14 (mean 8.09) for the SVN population, 2-10 (mean 7.73) for the SKH population, 2-17 (mean: 10.36) for the MMY population, and 2-9 (mean 6.36) for the MID population. The mean values of allele distribution with the expected heterozygosity $(\mathrm{He})$ marked for all populations are shown in Fig. 1. The observed heterozygosity (Ho) which determines the ratio between the heterozygous genotypes and the total number of genotypes per locus was between 0.36 and

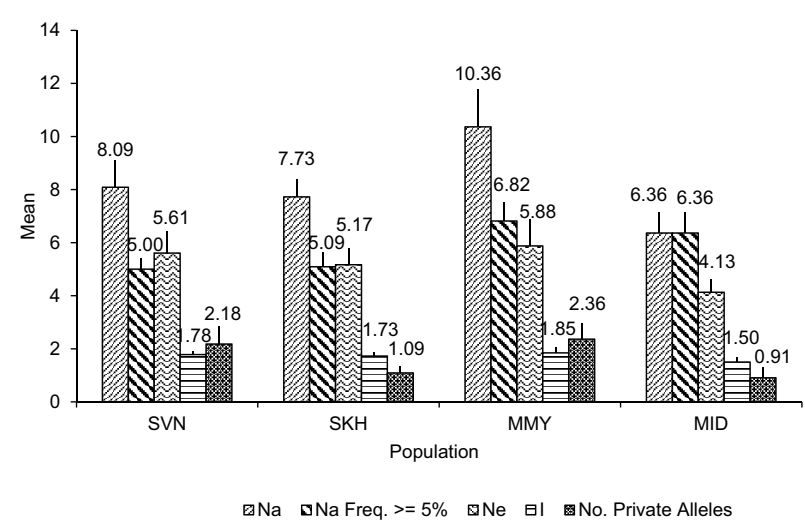

Fig. 1. Distribution of alleles in 11 microsatellite loci for the SVN, SKH, MMY, and MID populations of yellowstripe scad, Selaroides leptolepis; SVN = Vietnam, SKH $=$ Cambodia, $\mathrm{MMY}=$ Malaysia, $\mathrm{MID}=$ Indonesia; $\mathrm{Na}$ $=$ number of different alleles, $\mathrm{Ne}=$ number of effective alleles, I = Shannon's Information Index
0.91 (mean 0.65 ) for the SVN population, between 0.33 and 1.00 (mean 0.65) for the SKH population, between 0.00 and 0.95 (mean 0.70) for the MMY population, and between 0.11 and 0.79 (mean 0.63 ) for the MID population. Genetic diversity $(\mathrm{He})$ was between 0.44 and 0.85 (mean 0.77 ) for the SVN population, between 0.48 and 0.88 (mean 0.76) for the SKH population, between 0.1 and 0.92 (mean 0.47) for the MMY population, and between 0.11 and 0.82 (mean 0.69 ) for the MID population (Table 1). There were statistically significant deviations from the Hardy-Weinberg equilibrium: in the SVN population for loci Orla 16-32 and Orla $12-160$ at $P<0.001$ and $P<0.01$, respectively; in the SKH population for loci Orla 9-38, Orla 16-32 and Orla 20-134 at $P<0.01$, $P<0.05$ and $P<0.001$, respectively; in the MMY population for loci Orla 2-91, Orla 12-160, Orla 9-38 and Orla 20-134 at $P<0.001, P<0.05, P<0.01, P<0.001$, respectively; in the MID population for loci Orla 12-160 at $P<0.05$. Average genetic diversity of the SVN, SKH, MMY, and MID populations of yellowstripe scad, Selaroides leptolepis was presented in the Table 2 . The process of assigning randomly selected individuals to the baseline populations, based on the results of the species identification test, correctly indicated the origin of $75 \%$ of the analysed samples. The test was carried out using the significance level of 0.05 (Figs. 2 and 3 ).

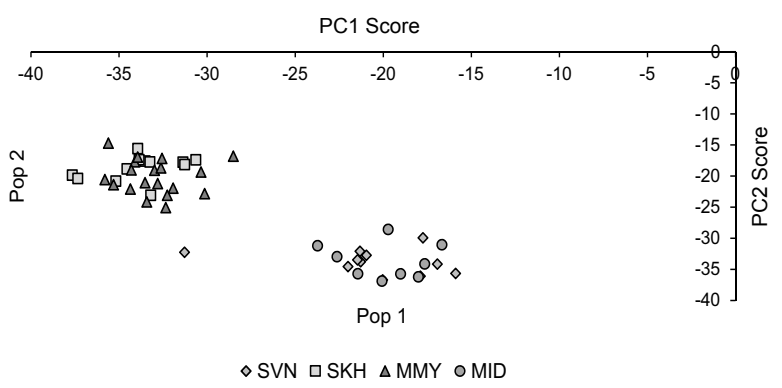

Fig. 2. Principal component analysis based on the genetic distances between individuals from the SVN, SKH, MMY, and MID populations of yellowstripe scad, Selaroides leptolepis; $\mathrm{SVN}=$ Vietnam, $\mathrm{SKH}=$ Cambodia, $\mathrm{MMY}=$ Malaysia, $\mathrm{MID}=$ Indonesia

\section{DISCUSSION}

Selaroides leptolepis is a species commonly occurring in the waters of the Indo-Pacific, quite extensively exploited in such countries as Malaysia (Chong et al. 2010) and the Philippines (Bacalso and Wolff 2014). In general, in countries with access to fresh fish of this species, they are consumed directly after catching, however, due to their affordable price, they have also been seen in Europe. In Germany, available is a "snack" product that is produced by smoking (E150), salting, and drying fillets of the yellowstripe scad. The price is 26.39 EUR per kg. However, the quality of the meat and its sanitary and parasitological evaluation pose a problem. According to Agusa et al. (2007), in the fish of the family Carangidae, originating from the coastal waters of Malaysia, high concentrations 
Table 1

Summary of Chi-square test for the assessment of the Hardy-Weinberg equilibrium in the SVN, SKH, MMY and MID populations of yellowstripe scad, Selaroides leptolepis

\begin{tabular}{|c|c|c|c|c|c|c|c|c|}
\hline Locus & Population & $\mathrm{df}$ & $\chi^{2}$ & $P$ & Population & $\mathrm{df}$ & $\chi^{2}$ & $P$ \\
\hline Orla 21-231 & SVN & 78 & 59.041 & 0.946 & MMY & 45 & 38.317 & 0.749 \\
\hline Orla $16-32$ & SVN & 21 & 47.972 & $0.001 * * *$ & MMY & 28 & 34.130 & 0.197 \\
\hline Orla 2-91 & SVN & 36 & 47.300 & 0.098 & MMY & 120 & 175.201 & $0.001 * * *$ \\
\hline Orla 22-135 & SVN & 28 & 31.005 & 0.317 & MMY & 136 & 113.531 & 0.920 \\
\hline Orla 5-131 & SVN & 91 & 91.056 & 0.479 & MMY & 136 & 137.222 & 0.455 \\
\hline Orla $12-160$ & SVN & 45 & 77.000 & $0.002 * *$ & MMY & 55 & 78.796 & $0.019^{*}$ \\
\hline Orla 16-185 & SVN & 36 & 36.667 & 0.438 & MMY & 28 & 14.711 & 0.981 \\
\hline Orla 8-113 & SVN & 10 & 10.368 & 0.409 & MMY & 45 & 27.431 & 0.982 \\
\hline Orla 9-204 & SVN & 15 & 9.625 & 0.843 & MMY & 28 & 26.061 & 0.570 \\
\hline Orla 9-38 & SVN & 6 & 11.688 & 0.069 & MMY & 21 & 42.708 & $0.003 * *$ \\
\hline Orla $20-134$ & SVN & 6 & 7.639 & 0.266 & MMY & 1 & 19.000 & $0.000 * * *$ \\
\hline Orla 21-231 & SKH & 28 & 21.000 & 0.825 & MID & 21 & 18.163 & 0.639 \\
\hline Orla $16-32$ & SKH & 28 & 56.328 & $0.001 * *$ & MID & 6 & 8.796 & 0.185 \\
\hline Orla 2-91 & SKH & 45 & 44.833 & 0.479 & MID & 28 & 25.000 & 0.628 \\
\hline Orla $22-135$ & SKH & 45 & 33.387 & 0.899 & MID & 36 & 38.000 & 0.378 \\
\hline Orla 5-131 & SKH & 45 & 55.053 & 0.145 & MID & 36 & 31.867 & 0.666 \\
\hline Orla $12-160$ & SKH & 28 & 37.083 & 0.117 & MID & 36 & 56.000 & $0.018^{*}$ \\
\hline Orla $16-185$ & SKH & 21 & 6.188 & 0.999 & MID & 15 & 17.438 & 0.293 \\
\hline Orla 8-113 & SKH & 28 & 30.080 & 0.359 & MID & 10 & 9.610 & 0.475 \\
\hline Orla 9-204 & SKH & 21 & 23.429 & 0.323 & MID & 28 & 25.240 & 0.615 \\
\hline Orla 9-38 & SKH & 21 & 34.720 & $0.03 *$ & MID & 1 & 0.031 & 0.860 \\
\hline Orla 20-134 & SKH & 1 & 7.252 & $0.007 * *$ & MID & 3 & 1.331 & 0.722 \\
\hline
\end{tabular}

$\mathrm{df}=$ degrees of freedom, calculated as $\mathrm{df}=[$ Number of alleles(Number of alleles -1$)] / 2, \chi^{2}=$ Chi-squared statistic $\chi^{2}, P=$ probability of obtaining the observed Chi-squared value $\left(* P<0.05,{ }^{*} P<0.01, * * * P<0.001\right)$.

Average genetic diversity of the SVN, SKH, MMY, and MID populations of yellowstripe scad,

Table 2 Selaroides leptolepis based on the analysis of 11 SSR loci

\begin{tabular}{ccccccccc}
\hline Population & $n$ & $\mathrm{Na}$ & $\mathrm{Ne}$ & $I$ & $\mathrm{Ho}$ & $\mathrm{He}$ & $\mathrm{uHe}$ & $F$ \\
\hline SVN & 11 & $8.091 \pm 1.013$ & $5.607 \pm 0.829$ & $1.785 \pm 0.147$ & $0.653 \pm 0.072$ & $0.772 \pm 0.040$ & $0.809 \pm 0.042$ & $0.159 \pm 0.077$ \\
SKH & 12 & $7.727 \pm 0.675$ & $5.170 \pm 0.612$ & $1.729 \pm 0.135$ & $0.645 \pm 0.084$ & $0.763 \pm 0.040$ & $0.796 \pm 0.042$ & $0.175 \pm 0.098$ \\
MMY & 19 & $10.364 \pm 1.410$ & $5.877 \pm 1.014$ & $1.846 \pm 0.207$ & $0.697 \pm 0.081$ & $0.741 \pm 0.070$ & $0.761 \pm 0.072$ & $0.134 \pm 0.095$ \\
MID & 9 & $6.364 \pm 0.766$ & $4.131 \pm 0.479$ & $1.501 \pm 0.169$ & $0.626 \pm 0.062$ & $0.687 \pm 0.067$ & $0.728 \pm 0.071$ & $0.064 \pm 0.053$ \\
\hline
\end{tabular}

Values are mean \pm standard error; $n=$ number of analysed fish, $\mathrm{Na}=$ number of alleles, $\mathrm{Ne}=$ number of effective alleles, $I=$ Shannon's Information Index, Ho observed heterozygosity, $\mathrm{He}=$ expected heterozygosity, $\mathrm{uHe}=$ unbiased expected heterozygosity, $F=$ Fixation Index (Inbreeding Coefficient).

of heavy metals, such as $\mathrm{V}, \mathrm{Cr}, \mathrm{Zn}, \mathrm{Pb}$, and $\mathrm{Bi}$, are not- only time when the quality of products from this species ed. Representatives of the same family from Indonesian imported to Germany from Vietnam was questioned was fisheries were characterised by the highest mean concen- in 2011 (as reported by the Border Veterinary Surgeon in tration of $\mathrm{Sn}$ and $\mathrm{Hg}$. The authors suggested a negative Szczecin). Questionable is also the quality of the meat impact of the consumption of those fish on the health of the from S. leptolepis as feedstock for the production of surimi general population of Southeast Asia. Taking into account or other low-processed products commonly consumed in the occurrence of the product on the EU market, registered Asian countries. The study by Peng et al. (2011) confirmed under the number EA8550, its safety should be a matter of that the species is a host for muscle larvae of Anisakis sp., particular attention. However, in the Rapid Alert System Contracaecum sp., and Porrocaecum sp. These parasites for Food and Feed of the European Union (RASFF), the are particularly dangerous to people consuming raw fish 
PC1 Score
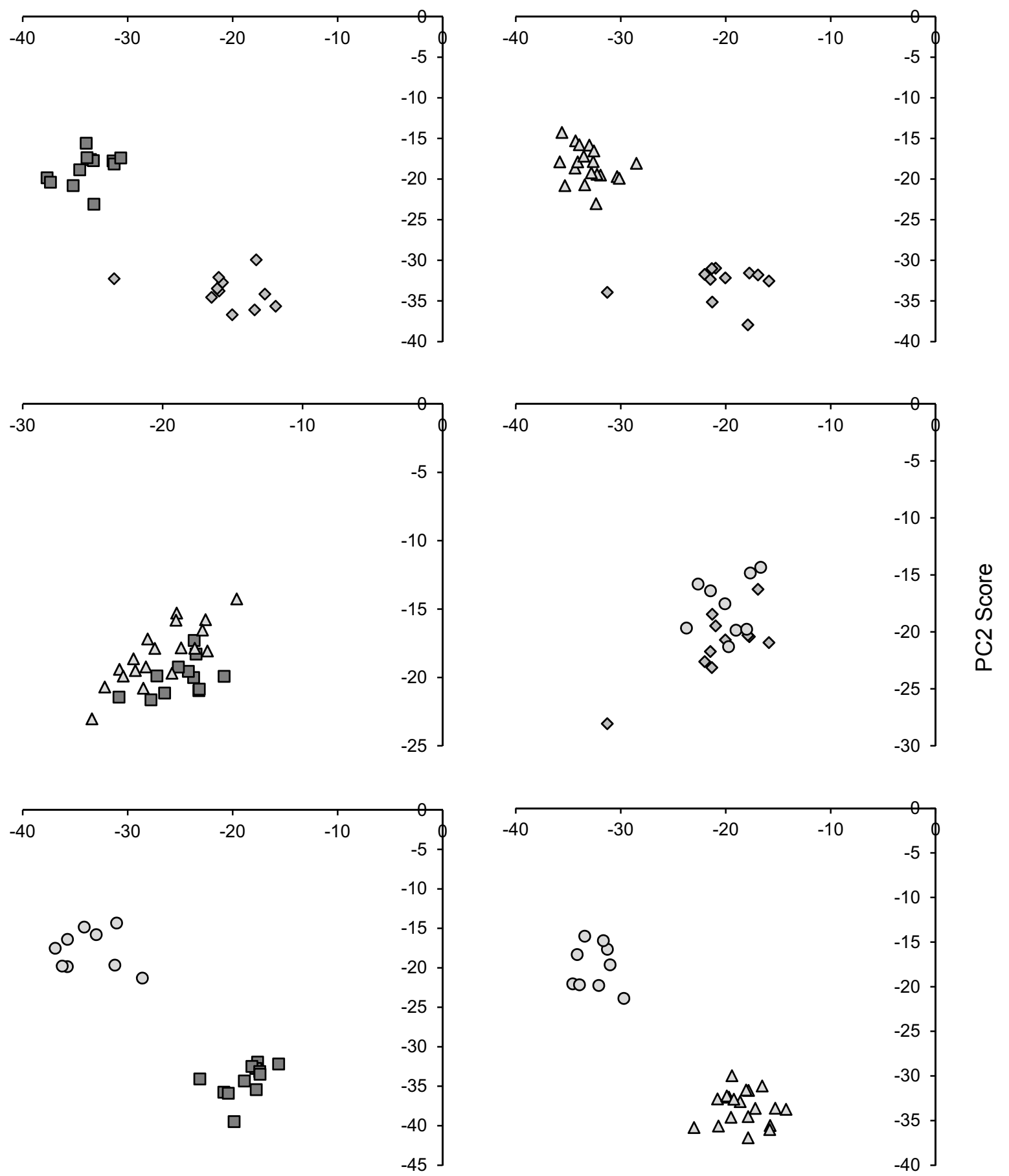

$\diamond$ SVN $\quad \square$ SKH $\quad \triangle$ MMY OMID

Fig. 3. Principal component analysis of inter-population genetic distances of yellowstripe scad, Selaroides leptolepis; $\mathrm{SVN}=$ Vietnam, $\mathrm{SKH}=$ Cambodia, $\mathrm{MMY}=$ Malaysia, $\mathrm{MID}=$ Indonesia

meat as they may cause a life-threatening parasitic disease known as anisakiosis (herring-worm disease, cod-worm disease). Studies indicate that it is not a species whose meat can be considered as of high quality, however, despite poor toxicological parameters, it is one of the main sources of proteins in the countries of Southeast Asia.

In the case of a species so intensively exploited, it is necessary to determine the characteristics of the population and locate safe places for fishing. This study demonstrated that populations caught in Vietnam and Indonesia, as well as Malaysia and Cambodia, are genetically homologous. Since the Malaysian population is in the worst condition and its consumption is harmful, a temporary restriction of fishing or additional monitoring should be introduced. The species is described as migratory between freshwater and ocean in both directions, its migrations are cyclic and its 
migration range is more than $100 \mathrm{~km}$. It appears, however, that the analysis of microsatellite loci confirms the hypothesis of isolation of schools/populations that do not mix genetically, which may be associated with the spatial or temporal separation of spawning of specific schools, or the existence of another mechanism of isolation (Figs. 2 and 3). In turn, the analysis of the mean genetic diversity of the populations, referred to as intraspecific variability, revealed the highest stability in the population caught in the coastal waters of Vietnam and the lowest stability in that of the coast of Malaysia. It is probable that the populations of this species are undergoing genetic regression due to overfishing and poor environmental conditions of the waters in the coastal zone of Indo-Pacific countries, especially near metropolitan areas, such as Jakarta, that do not have proper sewer systems. As was observed in this study, among the investigated fishing locations, the safest populations were those caught in the local fisheries (continental shelf) of Vietnam and Cambodia due to their high mean genetic diversity.

The exploitation of fisheries in the zone of continental shelf without respecting catch limits or permitted and safe catching methods causes degradation of unique ecosystems, such as the coastal coral reefs in the Philippines, or destabilizes the entire fish populations. In the case of Selaroides leptolepis of the Indo-Pacific region, there are still strong and genetically stable populations which should be particularly monitored by fishing law, while populations undergoing genetic degradation or constituting a part of diet dangerous to human health should be subject to separate fishing regulations and increased attention of veterinary services.

\section{ACKNOWLEDGEMENTS}

The presently reported study is the third part of a larger research project carried out within 2011-2014 and entitled " Development of a genetic-based system for identification of food products from fisheries and aquaculture introduced to the European Union customs area". The project was founded by the European Union (Operational Programme "Sustainable Development of the Fisheries Sector and Coastal Fishing Areas 2007-2013" No. 00002-611720-OR1600003/10) and administered by the Agency for Restructuring and Modernisation of Agriculture (ARiMR Poland). The project nicknamed CELFISH was carried out under auspices of- and in a close cooperation with the Customs Chamber in Szczecin (Izba Celna w Szczecinie).

\section{REFERENCES}

Agusa T., Kunito T., Sudaryanto A., Monirith A., Kan-Atireklap S., Iwata H., Ismail A., Sanguansin J., Muchtar M., Tana T.S., Tanabe S. 2007. Exposure assessment for trace elements from consumption of marine fish in Southeast Asia. Environmental Pollution 145 (3): 766-777.

DOI: $10.1016 /$ j.envpol.2006.04.034
Altschul S.F., Gish W., Miller W., Myers E.W., Lipman D.J. 1990. Basic local alignment search tool. Journal Molecular Biology 215 (3): 403-410.

DOI: $10.1016 / \mathrm{S} 0022-2836(05) 80360-2$

Anonymous 2015a. FAO major fishing areas for statistical purposes. FAO, Rome. http://www.fao.org/3/aaz126e.pdf

Anonymous 2015b. FAO, Fisheries and Aquaculture Department. Online query panels. http://www.fao.org/ fishery/topic/16140/en

Arfat Y.A., Benjakul S. 2012. Gelling characteristics of surimi from yellow stripe trevally (Selaroides leptolepis). International Aquatic Research 4: 5.

DOI: $10.1186 / 2008-6970-4-5$

Bacalso R.T.M., Wolff M. 2014. Trophic flow structure of the Danajon ecosystem (Central Philippines) and impact of illegal and destructive fishing practices. Journal of Marine Systems 139: 103-118.

DOI: 10.1016/j.jmarsys.2014.05.014

Chong V.C., Lee P.K.Y., Lau C.M. 2010. Diversity, extinction risk and conservation of Malaysian fishes. Journal of Biology 76 (9): 2009-2066. DOI: $10.1111 /$ j.1095-8649.2010.02685.x

Dell Q., Brewer D.T., Griffiths S.P., Heales D.S., Tonks M.L. 2009. Bycatch in a tropical schooling-Penaeid fishery and comparisons with a related, specialised trawl regime. Fisheries Management and Ecology 16 (3): 191-201. DOI: $10.1111 /$ j.1365-2400.2009.00655.x

Froese R., Pauly D. (eds.) 2014. FishBase. [version 08/2014] http://www.fishbase.org

Gotoh R.O., Tamate S., Yokoyama J., Tamate H.B., Hanzawa N. 2013. Characterization of comparative genome-derived simple sequence repeats for acanthopterygian fishes. Molecular Ecology Resources 13 (3): 461-472.

DOI: $10.1111 / 1755-0998.12070$

Gunn J.S. 1990. A revision of selected genera of the family Carangidae (Pisces) from Australian waters. Records of the Australian Museum 1990 (Suppl. 12): $1-77$.

DOI: $10.3853 /$ j.0812-7387.12.1990.92

Hall T.A. 1999. BioEdit: a user-friendly biological sequence alignment editor and analysis program for Windows 95/98/NT. Nucleic Acids Symposium Series (41): 95-98.

Jacquet J., Pauly D. 2008. Trade secrets: Renaming and mislabelling of seafood. Marine Policy 32 (3): 309318. DOI: 10.1016/j.marpol.2007.06.007

Peakall R., Smouse P.E. 2012. GenAlEx 6.5: genetic analysis in Excel. Population genetic software for teaching and research-an update. Bioinformatics 28 (19): 2537-2539.

DOI: 10.1093/bioinformatics/bts460

Peng W.-f., Liu S.-f., Wang B.-l., Wei M.-m. 2011. A checklist of parasitic nematodes from marine fishes of China. Systematic Parasitology 79 (1): 17-40.

DOI: $10.1007 / \mathrm{s} 11230-010-9288-1$ 
Rueca L.M., Bien N.B., Bathan R.M., Yuzon J.I., Sumaila U.R., Marsden A.D. Watson R., Pauly D. Salamat G.B. 2009. Fish Stock Assessment in Northern Zambales Coast (San Fernando, La Union: Bureau of Fisheries and Aquatic Resources Regional Office No. 3), 1, accessed January 14, 2013, http://nfrdi. da.gov.ph/techpaperseries/North\%20Zambales.pdf.

Sevilla R.G., Diez A., Norén M., Mouchel O., Jérôme M., Verrez-Bagnis V., van Pelt H., Favre-Krey L., Krey G., The FishTrace Consortium, Bautista J.M. 2007. Primers and polymerase chain reaction conditions for DNA barcoding teleost fish based on the mitochondrial cytochrome $b$ and nuclear rhodopsin genes. Molecular Ecology Notes 7 (5): 730-734. DOI: $10.1111 / \mathrm{j} .1471-8286.2007 .01863 . x$ 2007. A global ex-vessel fish price database: Construction and applications. Journal of Bioeconomics 9 (1): 39-51.

DOI: $10.1007 / \mathrm{s} 10818-007-9015-4$

Tan S.G., Yap C.K. 2006. Biochemical and molecular indicators in aquatic ecosystems: Current status and further applications in Malaysia. Aquatic Ecosystems Health and Management 9 (2): 227-236.

DOI: $10.1080 / 14634980600713620$

Tandon K.K. 1964. Biology and fishery of 'Choo Parai'-Selaroides leptolepis (Cuvier and Valenciennes). Part III. Population studies. Indian Journal of Fisheries 9 (1): 10-36.

Received: 15 December 2014

Accepted: 15 August 2015

Published electronically: 30 September 2015 